\section{Shiitake and Oyster Mushroom Production on Apple Pomace and Sawdust}

\author{
J.J. Worrall and C.S. Yang ${ }^{1}$ \\ College of Environmental Science and Forestry, State University of New \\ York, Syracuse, NY 13210
}

Additional index words. Lentinula edodes, Pleurotus spp., waste, bioconversion

\begin{abstract}
A mixture of apple pomace and sawdust was tested as a substrate for production of shiitake [Lentinula edodes (Berk.) Pegler] and oyster mushroom [Pleurotus ostreatus (Jacq. ex Fr.) Kummer and P. sajor-caju (Fr.) Sing.] on synthetic logs. MyCelia grew faster and more densely in logs containing apple pomace than in sawdust alone. Five shiitake isolates and two Pleurotus spp. produced higher fresh weights on a mixture of equal parts (by weight) of apple pomace and sawdust than on either substrate alone. An alternative substrate based on sawdust, millet (Panicum miliaceum L.), and wheat (Triticum aestivum L.), bran gave almost identical overall yield as pomace-sawdust medium, but there was a significant differential effect of the substrates on yield of the two tested shiitake isolates. Analyses and experiments in vitro suggested that optimal $\mathbf{N}$ levels provided by apple pomace account in part for its effectiveness.
\end{abstract}

Consumption of shiitake mushrooms has increased rapidly in recent decades and is expected to continue to grow. The fungus is traditionally cultivated on hardwood logs outdoors, but synthetic logs (sawdust with various amendments packed into bags and sterilized or pasteurized) under controlled conditions generally give higher yields in a shorter time (Royse et al., 1985). Controlled conditions also permit year-round production required in fresh markets.

Amendments such as oatmeal, cereal bran, corn meal, and millet have been tested in synthetic logs (Chang and Miles, 1989; Pettipher, 1988; Royse, 1985). Agricultural and even industrial waste materials such as cocoa shells, corn cobs, rice hulls, and pulp liquors have also been considered as amendments (Chang and Miles, 1989; Ohga, 1990). These

Received for publication 27 Nov. 1991. Accepted for publication 30 June 1992. This study was supPorted in part by the New York State Science and Technology Foundation. We thank D.H. Griffin, D.J. Royse, and R.A. Zabel for reviewing the manuscript and providing advice. The cost of publishing this paper was defrayed in part by the payment of page charges. Under postal regulations, this paper therefore must be hereby marked $a d$ vertisement solely to indicate this fact.

'Present address: 3 Greentree Way, Cherry Hill, NJ 08003 substrates have been successful in varying degrees, although generally there has not been a standard substrate with which they were compared. Development of a successful cultivation industry depends on local availability of inexpensive, suitable substrates.

In many parts of the northeastern United States and elsewhere, production of apple juice, cider, or sauce generates abundant pomace, or presscake waste. The major Processing plants produce $\approx 1.3$ million tons of apple pomace per year, not counting smaller cider mills. Annual disposal fees are estimated at \$10 million (Hang, 1987).

This report is an assessment of the potential of apple pomace as a major substrate for
2Percent moisture on basis of fresh weight.

yAcer saccharum. the production of shiitake and oyster mushrooms.

Apple pomace was collected within $24 \mathrm{~h}$ after pressing from Beak and Skiff Cider Mill, Lafayette, N.Y., and was frozen until use. Sawdusts of Quercus rubra L. (red oak), Fraxinus americana L. (white ash), and Acer saccharum Marsh. (sugar maple) were collected separately from local sawmills and contained bark and wood. Sawdust was used fresh or after air-drying. Hard red spring wheat bran and hulled white millet (both grown organically) were obtained from Community Mill and Beans, Savannah, N.Y.

Isolates (listed in Table 2) with the preface WC were obtained from Pennsylvania State Univ.; CSY 35 was isolated from shiitake spawn in Taiwan. Spawn was produced by inoculating sterile $A$. saccharum sawdust containing $1 \%(\mathrm{w} / \mathrm{w})$ malt extract.

Synthetic logs contained $500 \mathrm{~g}$ dry matter each. In the first experiment, logs contained either $100 \%$ apple pomace, $100 \%$ sawdust (ash or oak), or a 50:50 mixture on a dryweight basis. Fresh sawdust was used with 40\% moisture (fresh-weight basis), and 100 $\mathrm{ml}$ distilled water was added for every 250 g dry sawdust. Substrates were placed in polypropylene bags, which were stoppered with a foam plug $5 \mathrm{~cm}$ in diameter (used to provide aseptic aeration) and tightened with a wire tie. Logs were autoclaved at $121 \mathrm{C}$ for $90 \mathrm{~min}$. After cooling, each bag was inoculated with $\approx 10 \mathrm{~cm}^{3}$ spawn. Seven isolates were inoculated into each of five substrates with 12 replicates, for a total of $420 \operatorname{logs}$. Logs were incubated at $25 \mathrm{C}$ for 3 months and then moved in early May to a greenhouse, where the bags were opened. The greenhouse was held at 16C (day and night), but there was no humidity control; it tended to be dry with much air movement. The logs

Table 1. Formulations for comparison of apple pomace mixture with grain mixture.

\begin{tabular}{|c|c|c|c|c|}
\hline Mixture & Ingredient & Moisture $^{2}(\%)$ & Fresh wt (g) & Dry wt (g) \\
\hline Apple-sawdust & $\begin{array}{l}\text { Apple pomace } \\
\text { Sawdusty } \\
\text { Added water }\end{array}$ & $\begin{array}{c}77 \\
40 \\
---\end{array}$ & $\begin{array}{r}1098 \\
420 \\
\ldots . .\end{array}$ & $\begin{array}{r}250 \\
250 \\
\ldots\end{array}$ \\
\hline Total & & 67 & 1518 & 500 \\
\hline Grain-sawdust & $\begin{array}{l}\text { Wheat bran } \\
\text { White millet } \\
\text { Sawdust }{ }^{y} \\
\text { Added water }\end{array}$ & $\begin{array}{l}10.6 \\
10.6 \\
40 \\
\ldots- \\
39\end{array}$ & $\begin{array}{l}47.7 \\
47.7 \\
699 \\
25 \\
820\end{array}$ & $\begin{array}{l}42.7 \\
42.7 \\
416 \\
-\cdots \\
501\end{array}$ \\
\hline
\end{tabular}


Table 2. Yield of mushrooms on pomace, sawdust, and their mixtures.

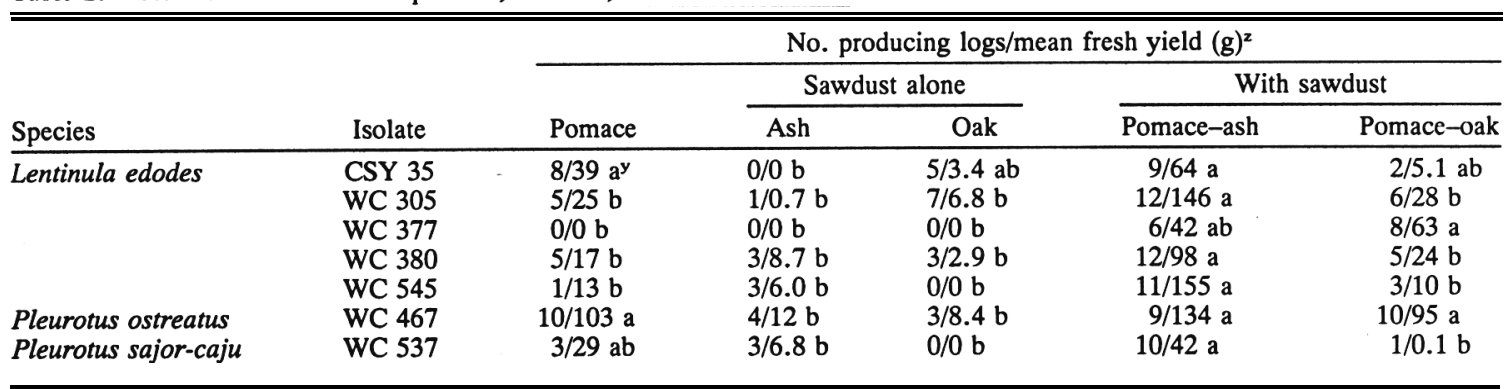

${ }^{\mathrm{z}}$ Twelve replicate logs were inoculated. Means include nonproducing logs (zero values).

${ }^{y}$ Means in a row followed by the same letter are in homoneneous groups $(P=0.05)$ according to a nonparametric simultaneous test procedure based on the Wilcoxon-Mann-Whitney statist; (Sokal and Rohlf, 1981).

Table 3. Yields of two shiitake isolates on synthetic sawdust logs amended with apple pomace. or grains. $^{\mathrm{z}}$

\begin{tabular}{llccc}
\hline \hline Mixture & Isolate & $\begin{array}{c}\text { Fresh wt/log } \\
(\mathrm{g})\end{array}$ & Mushrooms/log & $\begin{array}{c}\text { Fresh wt/ } \\
\text { mushroom (g) }\end{array}$ \\
\hline Pomace-sawdust & WC 305 & $135 \mathrm{a}^{\mathbf{x}}$ & $8.2 \mathrm{a}$ & $17.7 \mathrm{a}$ \\
& WC 545 & $84 \mathrm{~b}$ & $6.2 \mathrm{ab}$ & $13.3 \mathrm{~b}$ \\
Grain-sawdust & WC 305 & $61 \mathrm{~b}$ & $5.2 \mathrm{~b}$ & $12.9 \mathrm{~b}$ \\
& WC 545 & $159 \mathrm{a}$ & $14.4 \mathrm{c}$ & $11.7 \mathrm{~b}$ \\
\hline
\end{tabular}

${ }^{\mathrm{z}}$ See Table 1 for formulations.

${ }^{y}$ Logs contained $500 \mathrm{~g}$ dry substrate.

${ }^{x}$ Each value is the mean of 20 replicate logs, except for four bags that became contaminated during spawn run (isolate WC 545 on grain). Two-way analyses of variance showed highly significant substrate-isolate interaction for fresh weight per log and mushrooms per log. Means in a column followed by the same letter are in homogeneous groups according to LSD intervals $(P=0.05)$.

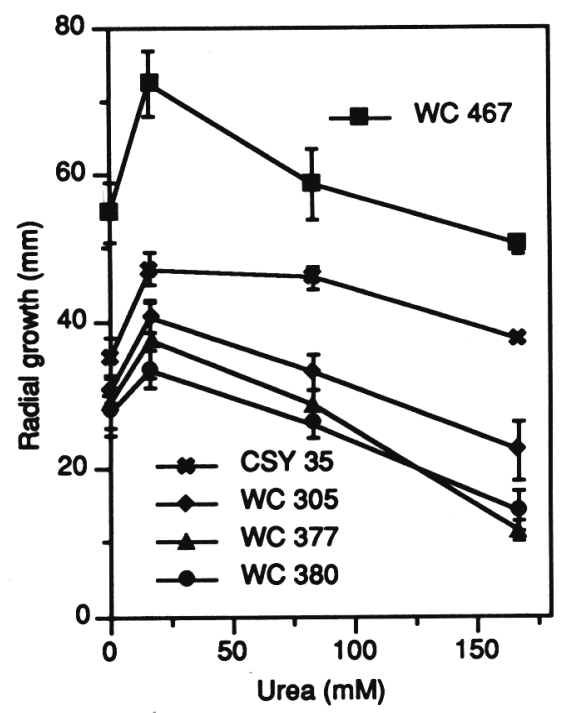

Fig. 1. Effect of urea nitrogen on radial growth of five isolates after 2 weeks. Each point is the mean of six replicates. Isolate WC 467 is Pleurotus ostreatus; the others are Lentinula edodes.

were watered three times per week.

Shiitake mushrooms were harvested when the veil ruptured; oyster mushrooms were harvested when they stopped expanding. For shiitake, fresh and dry weights were recorded; only fresh weights were recorded for oyster mushrooms. After 3 months in the greenhouse, the logs were removed and the experiment was terminated.

A second experiment was designed to compare shiitake production on a sawdust/ pomace mixture vs. a standard substrate incorporating sawdust (sugar maple), bran, and millet (Royse, 1985). Two isolates were used with 20 replicates. Formulations (Table 1) were planned such that equal dry weights were used, and moisture content of the grain mixture was adjusted to reproduce that used earlier (Royse, 1985). Logs were incubated, moved to the greenhouse in late June, and opened as above. Bags were removed 10 days after being opened. Logs were watered as before, except that they were soaked in water for $12 \mathrm{~h} 2$ weeks after the bags were removed.

Nitrogen requirements for mycelial growth were determined by adding urea to a basal medium containing (g-liter ${ }^{-1}$ ) 10 glucose, 1.75 $\mathrm{KH}_{2} \mathrm{PO}_{4}, 0.75 \mathrm{MgSO}_{4} \cdot 7 \mathrm{H}_{2} \mathrm{O}, 0.5 \mathrm{KC} 1,12$ agar, and $1.25 \mathrm{mg}$ thiamine at $\mathrm{pH}$ 5. A urea stock solution was filter-sterilized and added to cooled agar before being poured into petri dishes (final concentrations 0, 16.7, 83.3, and $166 \mathrm{~mm}$ urea). Agar plugs from the margins of active cultures on malt extract agar $(1.5 \%)$ were placed at the edge of each dish Total $\mathrm{N}$ was measured in pomace and sawdust by a Kjeldahl method.

Fresh apple pomace generally had $\approx 75 \%$ moisture (on a fresh-weight basis) and the $\mathrm{pH}$ was 3.8. Experience showed that it was unsuitable for use once a fermentative odor was detectable.

Mycelial growth was very sparse on sawdust alone. Mycelia on pomace were more dense but grew slowly. Dense, fast-growing mycelia were produced on the sawdust-pomace mixtures.

In many treatments, a substantial number of logs produced no mushrooms, resulting in a nonnormal distribution of mushroom yield. Inconsistency among $\operatorname{logs}$ is a common problem in shiitake production (Royse, 1985). Because the assumptions are not met, a standard analysis of variance (ANOVA) and multiple comparison procedure could not be used to compare the substrates. Instead, a nonparametric simultaneous test procedure based on the Wilcoxon-Mann-Whitney statistic was used for comparisons (Sokal and Rohlf, 1981).

Yield on sawdust alone was generally lower than that on other substrates (Table 2). The addition of pomace to ash caused significantly higher yields with six of the seven isolates. The addition of pomace to oak also increased yields, but this was significant in only two cases. Highest yields were generally obtained on the pomace-ash mixture.

The two highest-yielding isolates were chosen for a comparison of a sawdust-pomace mixture with the formulation based on sawdust, bran, and millet. Considering the isolates together, overall yield was nearly identical on the two substrates (Table 3). Mushrooms produced on the pomace formulation tended to be fewer but were heavier than those on the grain formulation. However, significance. tests of those relationships are not meaningful because a two-way ANOVA showed highly significant isolate-substrate interaction in fresh weight per log and number of mushrooms per log. Isolate WC 305 produced significantly better in the pomace than on the grain formulation; the reverse was true of isolate WC 545. This held true for both number and fresh weight of mushrooms per $\log$.

Nitrogen content of oven-dried pomace was $0.69 \%$. That of ash sawdust was $0.13 \%$. Growth on media containing urea was best at 16.7 and $83.8 \mathrm{~mm}$ (Fig. 1). Mycelia were much sparser in the basal medium than in the presence of any added urea.

These results suggest that apple pomace, a waste material that poses a disposal problem in many apple-growing regions, has potential for use in the production of exotic mushrooms such as shiitake and oyster mushroom. Apple pomace is rich in $\mathrm{N}$ as well as complex and readily usable carbohydrates (Hang, 1987) that complement the nutritional properties of sawdust.

When tested in vitro as urea, $\mathrm{N}$ concentrations in the range of $0.05 \%$ to $0.25 \%$ (corresponding approximately to 16.7-83.3 $\mathrm{mm}$ urea) gave the fastest linear growth. Our apple pomace contained $0.69 \%$ total N (dryweight basis). Nitrogen content of wood is usually $\approx 0.1 \%$ or less (Merrill and Cowling, 1966). Using our value of $0.13 \%$ for ash, the ash-pomace logs would contain $\approx 0.13 \%$ 
$\mathrm{N}$ (wet-weight basis). Thus, the pomace brings the overall $\mathrm{N}$ content well within the optimal range for rapid mycelial growth. Soluble sugars in the pomace may also contribute to rapid growth.

However, pomace alone was a poor substrate for mushroom production. The sawdust apparently balances the pomace by providing a reservoir of $\mathrm{C}$ and energy that is more slowly degraded after colonization is complete.

The poor performance of red oak in this study is anomalous. It is normally a preferred species for shiitake production. Handling at the mill may have introduced some deleterious materials.

The sawdust-pomace mixture compared favorably with the sawdust-grain mixture in yield. Yields in this study were lower than in a previous study of the latter mixture (Royse, 1985). Many handling practices may affect yield, but the most likely factor in this case is the lack of humidity control during fruiting in our study. In Royse's study, humidity was maintained at $95 \%$ to $98 \%$, and the logs were misted daily for several hours (Royse, 1985). As with any such comparison, results may vary depending on the exact conditions of the experiment.

As has been suggested (Chang and Miles, 1989), the relative productivity of isolates depends on the substrates used for fruiting. Conversely, comparisons of substrates depend on the isolates used for testing. A wider survey of isolates should be conducted to find those best suited for growth on the sawdust-pomace mixture.

Because apple pomace is a waste material, its use in mushroom production should not only be cheaper than grains and other primary products, but also contribute to reducing solid waste disposal problems. However, more work is needed before it can be recommended. Experiments should be conducted with a wider range of isolates under commercial fruiting conditions. Modifications of substrate moisture, $\mathrm{pH}$, etc. may also improve yields.

\section{Literature Cited}

Chang, ST. and P.G. Miles. 1989. Edible mushrooms and their cultivation. CRC, Boca Raton, Fla.

Hang, Y.D. 1987. Production of fields and chemicals from apple pomace. Food Technol. Mar.: 115-117.

Merrill, W. and E.B. Cowling. 1966. Role of nitrogen in wood deterioration: Amounts and distribution of nitrogen in tree stems. Can. J. Bot. 44:1555-1580.

Ohga, S. 1990. Effects of nutritional component on mycelial growth and fruit body yield of the shiitake mushroom, Lentinus edodes, on sawdust substrate. J. Faculty Agr., Kyushu Univ. 34:405-412.

Pettipher, G.L. 1988. Cultivation of the shiitake mushroom (Lenrinus edodes) on lignocellulosic waste. J. Sci. Food Agr. 42:195-198.

Royse, D.J. 1985. Effect of spawn run time and substrate nutrition on yield and size of the shiitake mushroom. Mycologia 77:756-762.

Royse, D.J., L.C. Schisler, and D.A. Diehle. 1985. Shiitake mushrooms-Consumption, produc- tion and cultivation. Interdisciplinary Sci. Rev. 10:329-335.
Sokal, R.R. and F.J. Rohlf. 1981. Biometry. 2nd ed. W.H. Freeman, San Francisco. 